\title{
Synthesis and Anti-Cancer Evaluation of Spiro-indolinone Derivatives
}

\author{
Liang Hong ${ }^{1}$, Jie Tong ${ }^{2}$, Guangliang $\mathrm{Yu}^{1}$, Chunqi $\mathrm{Hu}^{1,2^{\star}}$ \\ ${ }^{1}$ Yongning Pharma, Taizhou, PR China \\ ${ }^{2}$ College of Chemistry and Chemical Engineering, Shaoxing University, Shaoxing, PR China
}

\begin{abstract}
A series of spiro-indolin-2-one derivatives were designed and synthesized as p53-MDM2 binding inhibitors. Though p53-MDM2 binding inhibitory and activities against p53 wild-type cell lines of most compounds were not that promising, some obtained structures showed moderate to strong inhibitory activities $\left(\mathrm{IC}_{50}<0.08 \mu \mathrm{M}\right)$ against p53 mutant cell lines (SW620), suggesting that these compounds may have different modes of action to p53 pathway, further studies on treatment of p53 mutant tumors are under investigation.cc
\end{abstract}

Keywords: MDM2; p53; Spiro-indolinone; Anticancer

\section{Introduction}

The spiro-indolin-2-one compounds were synthesized by a series of compounds [1-3] with good p53-MDM2 binding inhibitory activity found in the structure-based design strategy of Wang and his group [4]. From the result of p53-MDM2 complex crystal structure [5], tryptophan residues on the indole ring of p53 is the most critical binding element for $\mathrm{p} 53$ binding MDM2 protein, which was buried in the hydrophobic pocket, and indole on the $\mathrm{NH}$ and MDM2 formed a hydrogen bond. Wang and his team members used computer-assisted drug screening to find compounds that mimic the indole ring and found that the structural properties of 2 -indolinone were most consistent with that of indole. 6-chloro-2-indolinone was identified as a predominant fragment on the basis of previous work on peptide compounds [6,7] and Nutlin (Trp pocket with key chlorine atoms capable of occupying MDM2 protein) [8].

The Spiro cyclic backbone provides the necessary platform for introducing side chains so that the hydrophobic side chains can be inserted into Leu and Phe pockets. The crystal structures of the resulting compounds MI-63 and MDM2 were recently reported by Popowicz et al. [8]. Interestingly, the MI-63 binding pattern is mirrored as previously assumed [9-11]. As previously assumed, 6-chloro-2indolinone occupies Trp pockets but the combination of neopentyl and substituted phenyl Mode and the previous hypothesis were reversed, suggesting that the conformation of the compound has been reversed, but the two states of MDM2 have a better inhibition. Based on the above studies, we designed a class of spiro-indolin-2-one compounds, in order to improve the class of compounds on MDM2 binding activity, and have a better anti-cancer effect (Figure 1). First, the hydrophobic groups such as methyl group, propionyl group and piperidine carboxyl group were introduced into pyrrole $\mathrm{N}$ to study the influence of different length or volume of hydrophobic groups on the activity. Then the effect of chlorine atom on the activity of 2 - indolinone was investigated. The effect of chlorine atom on the activity of benzene ring at the 4 ' position was investigated. And last the nitrogen-containing molecular fragments were introduced into the 4 'position of the pyrrole to enhance the watersolubility of the compounds, and the effects on the activity were also investigated.

\section{Chemistry}

The synthesis route of the spiro-indolin-2-one compounds was designed via systematic literature (Scheme 1).

Salicylaldehyde or substituted salicylaldehyde(1-2) and ethyl acetoacetate formed cyclization in the piperidine-catalyzed system to get acetyl coumarin compounds (6-7), And then reacted with isatin (3$5)$ and glycine or sarcosine $[2+3]$ cyclization to form spiro intermediate (8-13), Wherein the pyrrole 1'-methylated product (8-10) is directly reacted with the corresponding nitrogen-containing fragment to form (14-18); the remaining intermediates (11-13) are reacted with triphosgene and the corresponding amine to give the 4-methoxybenzyl protected intermediate (19-24), which is present in the presence of trifluoromethanesulfonic acid deprotection to get $\mathbf{2 5 - 3 0}$, and finally reacts with the corresponding nitrogen-containing heterocycle and fragment to yield the target product 31-43.

A total of 27 spiro-indolin-2-one compounds were synthesized by the method described above. The structures of the new compounds were confirmed by ${ }^{1} \mathrm{H}$ NMR MS and elemental analysis.

\section{Experiments}

\section{Biology}

Protein inhibitory test assay: Measurements were performed using an EnVision Multilabel Plate Reader with a $480 \mathrm{nM}$ excitation filter and a $535 \mathrm{nM}$ emission filter. The fluorescence polarization value FP was measured by incubating the test compound (DMSO <4\%) at a concentration of $10 \mu \mathrm{M}$ with the protein (final concentration of $10 \mathrm{nM}$ ) -fluorescence substrate (final concentration $1 \mathrm{nM}$ ) for $1 \mathrm{~h}$. Simultaneously, DMSO $(<4 \%)$ with the same dosing volume was incubated with the protein (final concentration of $10 \mathrm{nM}$ ) solution and the fluorescent substrate (final concentration of $1 \mathrm{nM}$ ), respectively, to test FPmax and FPmin. The inhibition of p53-MDM2 binding at the concentration of $10 \mu \mathrm{M}$ was calculated according to the following formula:

$$
\text { Inhibition } \%=1-\left(\mathrm{FP}^{-\mathrm{FP}_{\min }}\right) /\left(\mathrm{FP}_{\max }-\mathrm{FP}_{\min }\right)
$$

Cell viability assay (SRB assay): $100 \mu \mathrm{L}$ of cell suspension (A549, HCT116, SW620, and PC3 cells) was added to each well in a 96-well cell culture plate. The plate was incubated in a $\mathrm{CO}_{2}$ incubator for 24

${ }^{*}$ Corresponding author: Chunqi Hu, College of Chemistry and Chemical Engineering, Shaoxing University, Shaoxing, PR China, Tel: +8657588341521; Fax: +8657588341521; E-mail: hucq@usx.edu.cn

Received April 13, 2017; Accepted April 17, 2017; Published April 21, 2017

Citation: Hong L, Tong J, Yu G, Hu C (2017) Synthesis and Anti-Cancer Evaluation of Spiro-indolinone Derivatives. Med Chem (Los Angeles) 7: 846-852. doi: 10.4172/2161-0444.1000440

Copyright: ( 2017 Hong L, et al. This is an open-access article distributed under the terms of the Creative Commons Attribution License, which permits unrestricted use, distribution, and reproduction in any medium, provided the original author and source are credited. 


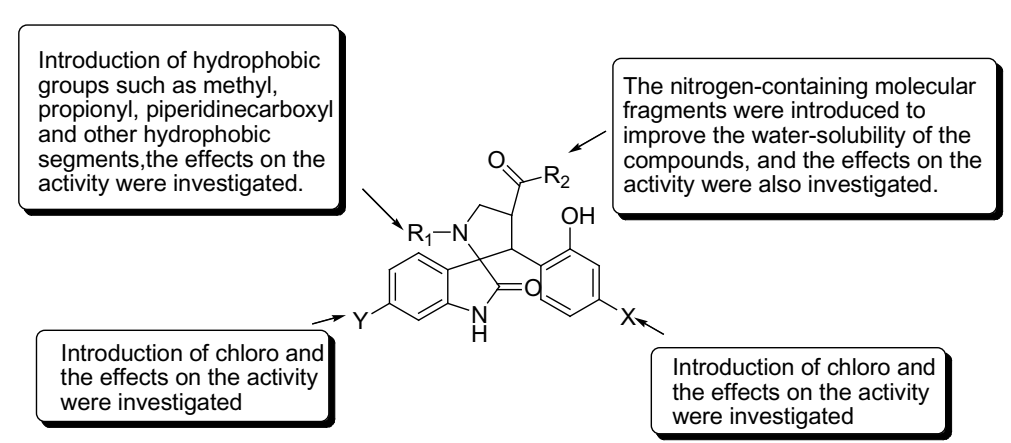

Figure 1: Strategy of Developing Novel Spiro-2-Indolinone Compounds.
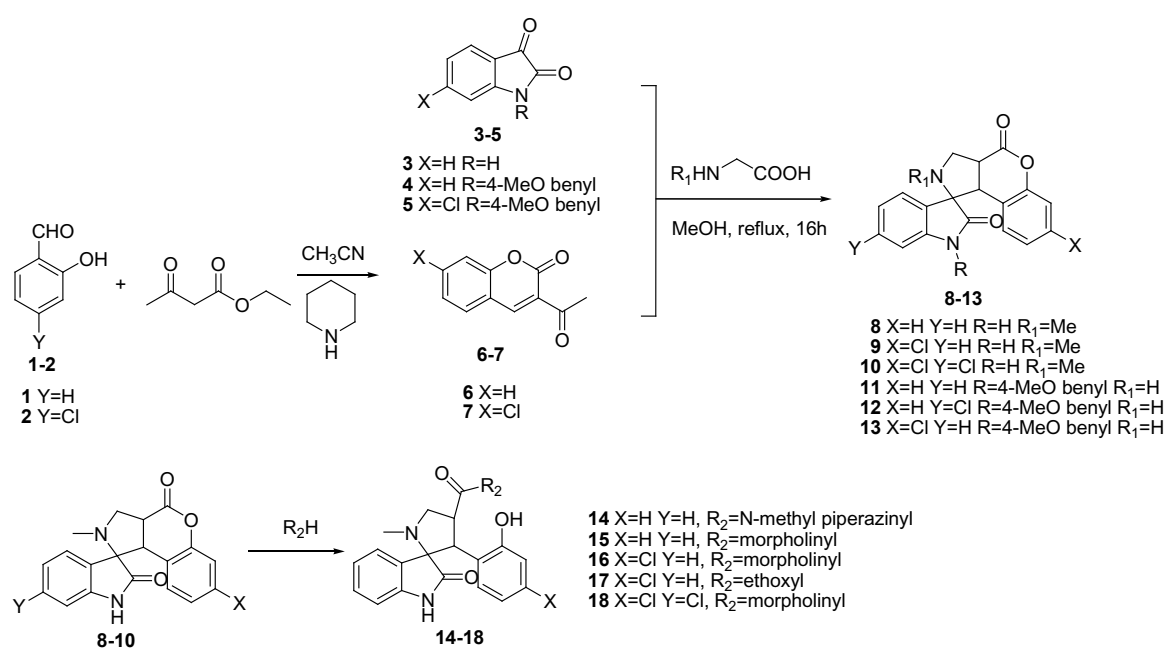

$8 \mathrm{X}=\mathrm{H} Y=\mathrm{H}$

$9 \mathrm{X}=\mathrm{Cl} Y=\mathrm{H}$
$10 \mathrm{X}=\mathrm{Cl} \mathrm{Y}=\mathrm{Cl}$

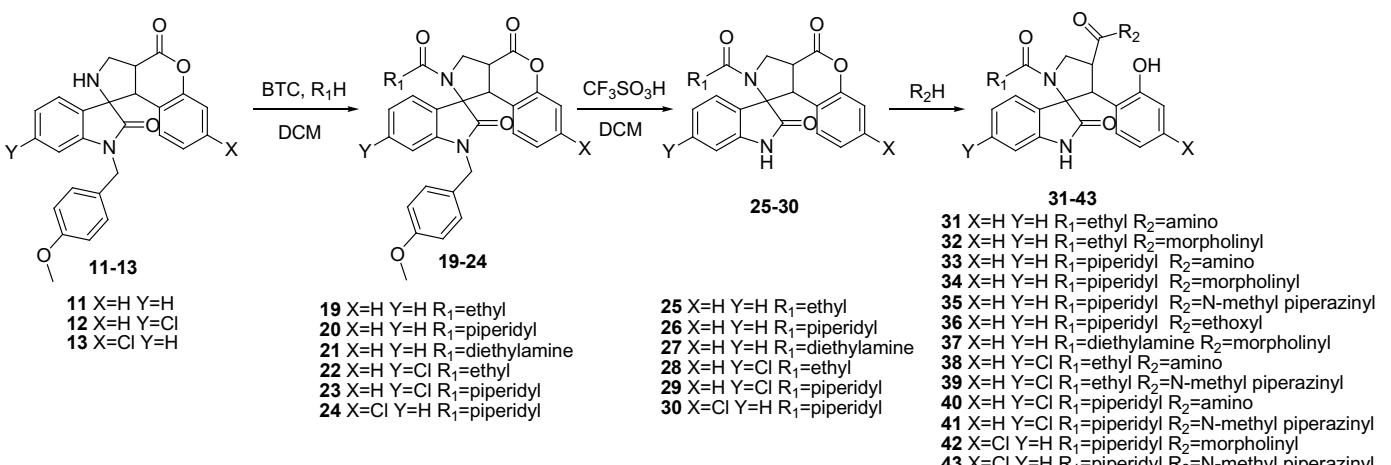

Scheme 1: The Synthetic Route of Spiro-indolinone Derivatives.

hours. After the culture plate was removed, a complete culture solution of the same concentration of each sample was added to each well. Three parallel wells were set up at each concentration, and A cells were added to the normal control wells $(\mathrm{C})$ without drug-containing complete culture. After that, the suction hole in the culture medium, deionized water washed 5 times. The plates were shaken on a microplate shaker and incubated in a $\mathrm{CO}_{2}$ incubator for 72 hours. The plate was removed and $50 \mu \mathrm{L}$ of $50 \%$ trichloroacetic acid (TCA) was added to each well. After standing for 5 minutes, the plate was allowed to stand at $4^{\circ} \mathrm{C}$ for
1 hour. Drain the fixative, wash with deionized water 5 times per well, dry and air dry. $100 \mu \mathrm{L}$ SRB solution was added to each well. After 10 minutes at room temperature, SRB bound to protein was washed 5 times with $1 \%$ acetic acid and air-dried. The bound SRB was lysed with $150 \mu \mathrm{L}$ of $10 \mathrm{mmol} / \mathrm{L}$ unbuffered Tris alkaline solution ( $\mathrm{pH} 10.5)$.

The cell inhibition rate was calculated by the following formula: Inhibitory $\%=\left(\mathrm{A} 515_{\text {control cells }}-\mathrm{A} 515_{\text {treated cells }}\right) / \mathrm{A} 515_{\text {control cells }} \times 100 \%$

(A515: OD under wavelength of $515 \mathrm{~nm}$ ) 
$\mathrm{IC}_{50}$ was calculated by the Fisher analysis. Assays were performed in triplicate to get the final data and SD values.

\section{Synthesis of 1-(4-methoxybenzyl)indoline-2,3-dione(4)}

Isatin $(2.0 \mathrm{~g}, 13 \mathrm{mmol})$ was dissolved in DMF $(20 \mathrm{~mL})$ in an ice bath, $\mathrm{NaH}$ (343 mg, $14.3 \mathrm{mmol}$ ) was added, after stirring under ice bathe for $30 \mathrm{~min}$, 4-methoxybenzylchloride $(1.94 \mathrm{~mL}, 14.3 \mathrm{mmol})$ was added, after $3 \mathrm{~h}$ in room temperature stirring, water was added to quench the reaction. The obtained red solid was recrystallized with ethyl estate and petroleum ether, and get a red solid 4. Yield: $67 \%$; M.P.: $167.6-168^{\circ} \mathrm{C}$ (Lit. 10: $169-171^{\circ} \mathrm{C}$ )

\section{Synthesis of 6-chloro-1-(4-methoxybenzyl)indoline-2,3- dione (5)}

6-Chloroindole (10.0 g, $55 \mathrm{mmol})$ was dissolved in DMSO (20 $\mathrm{mL})$ in an ice bath, $\mathrm{NaOH}(2.7 \mathrm{~g}, 66 \mathrm{mmol})$ was added, after stirring under ice bathe for $30 \mathrm{~min}$, 4-methoxybenzylchloride $(9.0 \mathrm{~mL}, 66$ $\mathrm{mmol}$ ) was added, after $3 \mathrm{~h}$ in room temperature stirring, water was added to quench the reaction. The obtained red solid was recrystallized with ethyl estate and petroleum ether, and get a red solid 6-chloro-1(4-methoxybenzyl) indoline; The obtained solid (5.0 g, $16 \mathrm{mmol}$ ) was dissolved in a mixture of acetone/Acetic acid $(3: 1,13 \mathrm{~mL})$ in an ice bath, then a solution of $\mathrm{CrO}_{3}(4.6 \mathrm{~g}, 46 \mathrm{mmol})$ in water $(15 \mathrm{~mL})$ was added slowly, and after stirring for $30 \mathrm{~min}$, the reaction mixture was diluted with water and extracted with ethyl estate, the obtained reddish oil was separated with column chromatography to get a poppy solid $\mathbf{5}$ $\left(0.63\right.$ g); Yield: $11 \%$; M.P.: $178-180^{\circ} \mathrm{C}$; MS (ESI): $302[\mathrm{M}+\mathrm{H}]^{+}$

\section{Synthesis of 3-acetyl-2H-chromen-2-one (6)}

To a refluxing mixture of salicylaldehyde (1) (200 mg, 1.64 mmol) and ethyl acetoacetate $(215 \mathrm{mg}, 1.64 \mathrm{mmol})$ in $\mathrm{CH}_{3} \mathrm{CN}(5$ $\mathrm{mL}$ ) was added freshly distilled piperidine $(6.75 \mathrm{mg}, 0.08 \mathrm{mmol})$. The reaction was monitored by TLC until the starting salicylaldehyde was consumed completely $(1.5 \mathrm{~h})$. After completion of the reaction, the filtrate was evaporated under reduced pressure; the obtained solid was recyrestallized by petroleum ether/ethyl estate to give $\mathbf{6}$ with excellent purity (over 99\%). Yield: 95\%; M.P.: $121-123^{\circ} \mathrm{C}$ (Lit. 8: $119-121^{\circ} \mathrm{C}$ ).

\section{Synthesis of 3-acetyl-7-chloro-2H-chromen-2-one (7)}

Synthesis of 3-acetyl-7-chloro-2H-chromen-2-one was obtained by using 4-chloro-2-hydroxybenzaldehyde instead of salicylaldehyde, according above reation. The obtained solid was recyrestallized by petroleum ether/ethyl estate to give 7 as a white solid. Yield: 92\%; M.P.: $167.6-168^{\circ} \mathrm{C}$; MS (ESI): $323[\mathrm{M}+\mathrm{H}]^{+}$.

\section{General method for the synthesis of compounds (8-13)}

Corresponding amino acids (2.0 mmol), 6 (or 7$)(2.0 \mathrm{mmol})$ and 3 (or 4 , or 5) $(2.0 \mathrm{mmol})$ was refluxing in methanol $(30 \mathrm{~mL})$ for 15 hours. After the reaction was done, the mixture was cooled to room temperature; the solid was filtered, and recrystallized in methanol, to get a white solid 8-13.

2-methyl-2,3,3a,9b-tetrahydro-4H-spiro [chromeno [3,4-c] pyrrole-1,3'-indole]-2',4(1'H)-dione (8): Yield: $80 \%$; M.P.: > 250 ${ }^{\circ} \mathrm{C}$ (Lit. $\left.{ }^{11}: 255-256^{\circ} \mathrm{C}\right) ;{ }^{1} \mathrm{H}$ NMR (500 MHz, DMSO) $\delta 10.35$ (s, NH, 1H), 7.64 (d, $J=7.2 \mathrm{~Hz}, \mathrm{Ar}-\mathrm{H}, 1 \mathrm{H}), 7.48(\mathrm{td}, J=7.7,1.0 \mathrm{~Hz}, \mathrm{Ar}-\mathrm{H}, 1 \mathrm{H}), 7.42(\mathrm{~m}$, Ar-H, 1H), 7.32 (d, J=7.3 Hz, Ar-H, 1H), 7.17 (d, J=7.7 Hz, Ar-H, 1H), $7.01(\mathrm{td}, J=7.6,0.8 \mathrm{~Hz}, \mathrm{Ar}-\mathrm{H}, 1 \mathrm{H}), 6.90(\mathrm{~d}, J=7.7 \mathrm{~Hz}, \mathrm{Ar}-\mathrm{H}, 1 \mathrm{H}), 6.41(\mathrm{~d}$, $J=6.7 \mathrm{~Hz}, \mathrm{Ar}-\mathrm{H}, 1 \mathrm{H}), 4.12(\mathrm{~d}, J=10.9 \mathrm{~Hz}, \mathrm{CH}, 1 \mathrm{H}), 4.09(\mathrm{~m}, \mathrm{CH}, 1 \mathrm{H})$, $3.96(\mathrm{t}, J=9.1 \mathrm{~Hz}, \mathrm{CH}, 1 \mathrm{H}), 3.68(\mathrm{dd}, J=9.1,4.4 \mathrm{~Hz}, \mathrm{CH}, 1 \mathrm{H}), 2.22(\mathrm{~s}$, $\left.\mathrm{CH}_{3}, 3 \mathrm{H}\right) ; \mathrm{MS}$ (ESI): $321[\mathrm{M}+\mathrm{H}]^{+}$. Anal. Calcd for $\mathrm{C}_{19} \mathrm{H}_{16} \mathrm{~N}_{2} \mathrm{O}_{3}: \mathrm{C}, 71.24$;
H, 5.03; N, 8.74; Found: C, 71.14; H, 5.01; N, 8.84.

7 - chloro- 2 - m e thy - 2, 3, 3 a , 9 b - t e tra hydro- $4 \mathrm{H}$ spiro[chromeno[3,4-c]pyrrole-1,3'-indole]-2',4(1'H)-dione (9): Yield: $75 \%$; M.P.: $>250^{\circ} \mathrm{C}$; ${ }^{1} \mathrm{H}$ NMR $\left(500 \mathrm{MHz} \mathrm{CDCl}_{3}\right) \delta 7.33(\mathrm{t}, J=7.5$ $\mathrm{Hz}, \mathrm{Ar}-\mathrm{H}, 1 \mathrm{H}), 7.20$ (t, J=7.5 Hz, Ar-H, 1H), 7.17 (m, Ar-H, 1H), 6.96 (d, J=8.2 Hz, Ar-H, 1H), 6.76 (ddd, J=12.0, 6.2, 2.4 Hz, Ar-H, 2H), 6.31 (m, Ar-H, 1H), 3.95 (s, CH, 1H), 3.88 (d, J=9.2 Hz, CH, 1H), 3.81 (d, $J=5.2 \mathrm{~Hz}, \mathrm{CH}, 1 \mathrm{H}), 3.61(\mathrm{td}, J=10.3,4.7 \mathrm{~Hz}, \mathrm{CH}, 1 \mathrm{H}), 2.18\left(\mathrm{~s}, \mathrm{CH}_{3}, 3 \mathrm{H}\right)$; MS (ESI): $355[\mathrm{M}+\mathrm{H}]^{+}$. Anal. Calcd for $\mathrm{C}_{19} \mathrm{H}_{15} \mathrm{ClN}_{2} \mathrm{O}_{3}: \mathrm{C}, 64.32 ; \mathrm{H}, 4.26$; N, 7.90; Found: C, 64.22; H, 4.36; N, 7.82.

$6^{\prime}, 7$ - dichloro-2 - methyl-2,3,3 a,9b-tetrahydro-4 Hspiro[chromeno[3,4-c]pyrrole-1,3'-indole]-2',4(1'H)-dione (10): Yield: $58 \%$; M.P.: $>250{ }^{\circ} \mathrm{C}$; ${ }^{1} \mathrm{H}$ NMR $\left(500 \mathrm{MHz} \mathrm{CDCl}_{3}\right) \delta 10.37$ (s, NH, $1 \mathrm{H}), 7.48$ (d, J=8.0 Hz, Ar-H, 1H), 7.30 (m, Ar-H, 2H), 7.00 (dd, $J=8.3$, $2.1 \mathrm{~Hz}, \mathrm{Ar}-\mathrm{H}, 1 \mathrm{H}), 6.76$ (d, J=1.8 Hz, Ar-H, $1 \mathrm{H}), 6.31$ (d, $J=8.3 \mathrm{~Hz}, \mathrm{Ar}-$ $\mathrm{H}, 1 \mathrm{H}), 4.15(\mathrm{~m}, \mathrm{CH}, 1 \mathrm{H}), 3.98(\mathrm{~d}, J=10.9 \mathrm{~Hz}, \mathrm{CH}, 1 \mathrm{H}), 3.89(\mathrm{~m}, \mathrm{CH}$, $1 \mathrm{H}), 3.79$ (t, J=9.2 Hz, CH, 1H), 3.46 (dd, J=9.3, $4.4 \mathrm{~Hz}, \mathrm{CH}, 1 \mathrm{H}), 2.03$ (s, $\left.\mathrm{CH}_{3}, 3 \mathrm{H}\right) ; \mathrm{MS}(\mathrm{ESI}): 390[\mathrm{M}+\mathrm{H}]^{+}$. Anal. Calcd for $\mathrm{C}_{19} \mathrm{H}_{14} \mathrm{Cl}_{2} \mathrm{~N}_{2} \mathrm{O}_{3}: \mathrm{C}$, 58.63; H, 3.63; N, 7.20; Found: C, 58.55; H, 3.68; N, 7.24.

\section{General method for the synthesis of compounds 14-18}

8-10 (50 mg, $0.16 \mathrm{mmol})$ was dissolved in THF $(6 \mathrm{~mL})$, corresponding amine $(0.48 \mathrm{mmol})$ was added, after refluxing for $\mathrm{min}$, the solvent was removed by rotary evaporation and the residue was extracted by ethyl estate and water, the organic layer was kept and washed with brine $(3 \times 10 \mathrm{~mL})$, dried with sodium sulfate, then removed the solvent, the obtained solid was recrystallized in ethyl estate/petroleum ether and get a white solid 14-18.

3'-(2-hydroxyphenyl)-1'-methyl-4'-[(4-methylpiperazin-1-yl) carbonyl] spiro[indole-3,2'-pyrrolidin]-2(1H)-one (14): Yield: $85 \%$; M.P.: $128-130^{\circ} \mathrm{C} ;{ }^{1} \mathrm{H}$ NMR $\left(500 \mathrm{MHz}, \mathrm{CDCl}_{3}\right) \delta 7.85$ (s, OH, $\left.1 \mathrm{H}\right), 7.53$ (d, J=7.5 Hz, Ar-H, 1H), 7.25 (m, Ar-H, 1H), 7.15 (t, J=7.7 Hz, Ar-H, 1H), 7.04 (dd, $J=13.7,6.6 \mathrm{~Hz}, \mathrm{Ar}-\mathrm{H}, 2 \mathrm{H}), 6.84(\mathrm{~d}, J=8.0 \mathrm{~Hz}, \mathrm{Ar}-\mathrm{H}, 1 \mathrm{H})$, $6.69(\mathrm{dd}, J=7.5,4.1 \mathrm{~Hz}, \mathrm{Ar}-\mathrm{H}, 2 \mathrm{H}), 4.50(\mathrm{~d}, J=9.6 \mathrm{~Hz}, \mathrm{CH}, 1 \mathrm{H}), 4.03(\mathrm{td}$, $J=10.1,6.0 \mathrm{~Hz}, \mathrm{CH}, 1 \mathrm{H}), 3.77\left(\mathrm{~m}, \mathrm{CH}_{2} \times 2,4 \mathrm{H}\right), 3.40(\mathrm{t}, J=7.2 \mathrm{~Hz}, 3 \mathrm{H})$, $2.35\left(\mathrm{t}, J=5.1 \mathrm{~Hz}, \mathrm{CH}_{3}, 3 \mathrm{H}\right), 2.31(\mathrm{~m}, 6 \mathrm{H}), 2.16\left(\mathrm{~s}, \mathrm{CH}_{3}, 3 \mathrm{H}\right)$; MS (ESI): $421[\mathrm{M}+\mathrm{H}]^{+}$. Anal. Calcd for $\mathrm{C}_{24} \mathrm{H}_{28} \mathrm{~N}_{4} \mathrm{O}_{3}: \mathrm{C}, 68.55 ; \mathrm{H}, 6.71 ; \mathrm{N}, 13.32$; Found: C, 68.57; H, 6.73; N, 13.28.

3'-(2-hydroxyphenyl)-1'-methyl-4'-(morpholin-4-ylcarbonyl) spiro[indole-3,2'-pyrrolidin]-2(1H)-one (15): Yield: 87\%; M.P.: 120 $122^{\circ} \mathrm{C} ;{ }^{1} \mathrm{H}$ NMR $\left(500 \mathrm{MHz}, \mathrm{CDCl}_{3}\right) \delta 7.79(\mathrm{~s}, \mathrm{OH}, 1 \mathrm{H}), 7.56(\mathrm{~d}, J=7.4$ $\mathrm{Hz}, \mathrm{Ar}-\mathrm{H}, 1 \mathrm{H}), 7.17$ (dd, J=12.2, $4.4 \mathrm{~Hz}, \mathrm{Ar}-\mathrm{H}, 2 \mathrm{H}), 7.09$ (m, Ar-H, 2H), $6.85(\mathrm{~d}, J=8.0 \mathrm{~Hz}, \mathrm{Ar}-\mathrm{H}, 1 \mathrm{H}), 6.71$ (dd, J=9.4, 7.8 Hz, Ar-H, 2H), 4.45 (d, $J=9.4 \mathrm{~Hz}, \mathrm{CH}, 1 \mathrm{H}), 4.05(\mathrm{td}, J=9.9,6.0 \mathrm{~Hz}, \mathrm{CH}, 1 \mathrm{H}), 3.73\left(\mathrm{~m}, \mathrm{CH}_{2} \times 3\right.$, $6 \mathrm{H}), 3.49\left(\mathrm{~m}, \mathrm{CH}_{2} \times 2,4 \mathrm{H}\right), 2.17\left(\mathrm{~s}, \mathrm{CH}_{3}, 3 \mathrm{H}\right) ; \mathrm{MS}(\mathrm{ESI}): 408[\mathrm{M}+\mathrm{H}]^{+}$. Anal. Calcd for $\mathrm{C}_{23} \mathrm{H}_{25} \mathrm{~N}_{3} \mathrm{O}_{4}$ : C, 67.80; H, 6.18; N, 10.31; Found: C, 67.78; H, 6.14; N, 10.33 .

3'-(4-chloro-2-hydroxyphenyl)-1'-methyl-4'-(morpholin-4ylcarbonyl)spiro[indole-3,2'-pyrrolidin]-2(1H)-one (16): Yield: $83 \%$; M.P.: $140-143^{\circ} \mathrm{C} ;{ }^{1} \mathrm{H}$ NMR $\left(500 \mathrm{MHz}, \mathrm{CDCl}_{3}\right) 7.46(\mathrm{~d}, J=7.4 \mathrm{~Hz}, \mathrm{Ar}-\mathrm{H}$, 1H), $7.18(\mathrm{~m}, \mathrm{Ar}-\mathrm{H}, 2 \mathrm{H}), 7.10(\mathrm{~m}, \mathrm{Ar}-\mathrm{H}, 2 \mathrm{H}), 6.85$ (d, J=8.0 Hz, Ar-H, $1 \mathrm{H}), 6.71(\mathrm{dd}, J=9.4,7.8 \mathrm{~Hz}, \mathrm{Ar}-\mathrm{H}, 2 \mathrm{H}), 4.45(\mathrm{~d}, J=9.4 \mathrm{~Hz}, \mathrm{CH}, 1 \mathrm{H}), 4.05$ $(\mathrm{td}, J=9.9,6.0 \mathrm{~Hz}, \mathrm{CH}, 1 \mathrm{H}), 3.70\left(\mathrm{~m}, \mathrm{CH}_{2} \times 3,6 \mathrm{H}\right), 3.53\left(\mathrm{~m}, \mathrm{CH}_{2} \times 2,4 \mathrm{H}\right)$, $2.17\left(\mathrm{~s}, \mathrm{CH}_{3}, 3 \mathrm{H}\right)$; $\mathrm{MS}(\mathrm{ESI}): 442[\mathrm{M}+\mathrm{H}]^{+}$. Anal. Calcd for $\mathrm{C}_{23} \mathrm{H}_{24} \mathrm{ClN}_{3} \mathrm{O}_{4}$ : C, 62.51; H, 5.47; N, 9.51; Found: C, 62.55; H, 5.49; N, 9.41.

3'-(4-chloro-2-hydroxyphenyl)- $N$-(2-hydroxyethyl)-1'-methyl-2oxo-1,2 dihydrospiro[indole-3,2'-pyrrolidine]-4'-carboxamide (17): Yield: $60 \%$; M.P.: $124-126^{\circ} \mathrm{C}$; ${ }^{1} \mathrm{H}$ NMR $(500 \mathrm{MHz}, \mathrm{MeOD}) \delta 7.44(\mathrm{~d}$, 
$J=7.4 \mathrm{~Hz}, \mathrm{Ar}-\mathrm{H}, 1 \mathrm{H}), 7.26(\mathrm{t}, J=7.7 \mathrm{~Hz}, \mathrm{Ar}-\mathrm{H}, 1 \mathrm{H}), 7.08$ (dd, $J=7.9,6.3$ $\mathrm{Hz}, \mathrm{Ar}-\mathrm{H}, 2 \mathrm{H}), 6.85$ (d, J=7.7 Hz, Ar-H, 1H), 6.66 (d, J=2.1 Hz, Ar-H, $1 \mathrm{H}), 6.62(\mathrm{dd}, J=8.3,2.2 \mathrm{~Hz}, \mathrm{Ar}-\mathrm{H}, 1 \mathrm{H}), 4.42(\mathrm{~d}, J=10.0 \mathrm{~Hz}, \mathrm{CH}, 1 \mathrm{H})$, $3.91(\mathrm{dt}, J=12.4,8.8 \mathrm{~Hz}, \mathrm{CH}, 2 \mathrm{H}), 3.29$ (dd, $J=11.7,5.6 \mathrm{~Hz}, \mathrm{CH}, 2 \mathrm{H})$, 3.07 (dd, J=11.3, $6.1 \mathrm{~Hz}, \mathrm{CH}, 2 \mathrm{H}$ ); MS (ESI): 416[M+H] ${ }^{+}$. Anal. Calcd for $\mathrm{C}_{21} \mathrm{H}_{22} \mathrm{ClN}_{3} \mathrm{O}_{4}$ : C, 60.65; H, 5.33; N, 10.10; Found: C, 60.61; H, 5.39; $\mathrm{N}, 10.12$.

6-chloro-3'-(4-chloro-2-hydroxyphenyl)-1'-methyl-4'(morpholin-4-ylcarbonyl)spiro[indole-3,2'-pyrrolidin]-2(1H)-one (18): Yield: 60\%; M.P.: $165-168^{\circ} \mathrm{C}$; ${ }^{1} \mathrm{H}$ NMR $(500 \mathrm{MHz}, \mathrm{MeOD}) \delta 7.42$ (m, Ar-H, 1H), 7.31 (s, Ar-H, 1H), 7.05 (t, J=6.4 Hz, Ar-H, 1H), 6.65 (dd, $J=10.7,4.3 \mathrm{~Hz}, \mathrm{Ar}-\mathrm{H}, 2 \mathrm{H}), 6.63(\mathrm{~m}, \mathrm{Ar}-\mathrm{H}, 1 \mathrm{H}), 4.46$ (d, $J=10.3$ $\mathrm{Hz}, \mathrm{CH}, 1 \mathrm{H}), 3.85$ (t, J=14.5 Hz, CH, 2H), $3.73(\mathrm{~m}, \mathrm{CH}, 1 \mathrm{H}), 3.51$ (dd, $\left.J=35.5,25.8 \mathrm{~Hz}, \mathrm{CH}_{2} \times 2,4 \mathrm{H}\right), 3.09\left(\mathrm{~m}, \mathrm{CH}_{2} \times 2,4 \mathrm{H}\right), 2.21(\mathrm{~d}, J=19.1 \mathrm{~Hz}$, $\left.\mathrm{CH}_{3}, 3 \mathrm{H}\right) ; \mathrm{MS}(\mathrm{ESI}): 476[\mathrm{M}+\mathrm{H}]^{+}$. Anal. Calcd for $\mathrm{C}_{23} \mathrm{H}_{23} \mathrm{Cl}_{2} \mathrm{~N}_{3} \mathrm{O}_{4}: \mathrm{C}$, 57.99; H, 4.87; N, 8.82; Found: C, 57.88; H, 4.89; N, 8.84.

\section{General method for the synthesis of compound 25 or 28}

Compounds $\mathbf{2 5}$ or $\mathbf{2 8}$ were obtained by two steps. First, the obtained 11-13 (0.47 mmol) were dissolved in methylene chloride (15 $\mathrm{mL})$, then propionyl chloride $(0.94 \mathrm{mmol})$ was added, after stirring till the starting material was finished, the solvent was removed, the residue was re-dissolved in methylene chloride $(10 \mathrm{~mL})$ again, and trifluoromethanesulfonic acid $(0.47 \mathrm{mmol})$ was added dropwise over night in room temperature. After the reaction was done, the solvent was removed, extracted with methylene chloride and water, keep the organic, and washed with brine, dried with sodium sulfate. Remove the solvent and the obtained solid was crystallized with ethyl estate and petroleum ether to get a white solid $\mathbf{2 5}$ or $\mathbf{2 8}$.

2-propionyl-2,3,3a,9b-tetrahydro-4H-spiro[chromeno[3,4-c] pyrrole-1,3'-indole]-2',4(1'H)-dione (25): Total Yield: 45\%; M.P.: > $250^{\circ} \mathrm{C} ;{ }^{1} \mathrm{H}$ NMR $\left(500 \mathrm{MHz}, \mathrm{CDCl}_{3}\right) \delta 7.26(\mathrm{~m}, \mathrm{Ar}-\mathrm{H}, 2 \mathrm{H}), 7.12(\mathrm{t}, J=7.5$ $\mathrm{Hz}, \mathrm{Ar}-\mathrm{H}, 1 \mathrm{H}), 7.08$ (m, Ar-H, 2H), 6.86 (td, J=7.5, $1.0 \mathrm{~Hz}, \mathrm{Ar}-\mathrm{H}, 1 \mathrm{H})$, $6.74(\mathrm{~d}, J=7.7 \mathrm{~Hz}, \mathrm{Ar}-\mathrm{H}, 1 \mathrm{H}), 6.34(\mathrm{~m}, \mathrm{Ar}-\mathrm{H}, 1 \mathrm{H}), 4.85$ (d, $J=10.4 \mathrm{~Hz}$, $\mathrm{CH}, 1 \mathrm{H}), 4.18$ (dd, J=10.6, $6.9 \mathrm{~Hz}, \mathrm{CH}, 1 \mathrm{H}), 3.96(\mathrm{~d}, J=8.8 \mathrm{~Hz}, \mathrm{CH}$, $1 \mathrm{H}), 3.48(\mathrm{~m}, \mathrm{CH}, 1 \mathrm{H}), 2.53(\mathrm{dd}, J=16.6,7.4 \mathrm{~Hz}, \mathrm{CH}, 1 \mathrm{H}), 2.35(\mathrm{dd}$, $J=16.6,7.4 \mathrm{~Hz}, \mathrm{CH}, 1 \mathrm{H}$ ), 1.08 (dd, $J=9.4,5.4 \mathrm{~Hz}, \mathrm{CH}_{3}, 3 \mathrm{H}$ ); MS (ESI): $363[\mathrm{M}+\mathrm{H}]^{+}$. Anal. Calcd for $\mathrm{C}_{21} \mathrm{H}_{18} \mathrm{~N}_{2} \mathrm{O}_{4}: \mathrm{C}, 69.60 ; \mathrm{H}, 5.01 ; \mathrm{N}, 7.73$; Found: C, 69.70; H, 5.11; N, 7.63.

6 ' - chloro-2-propionyl-2,3,3a,9b-tetrahydro- $4 \mathrm{H}$ spiro[chromeno[3,4-c]pyrrole-1,3'-indole]-2',4(1'H)-dione (28): Yield: 52\%; M.P.: > $250{ }^{\circ} \mathrm{C} ;{ }^{1} \mathrm{H}$ NMR $\left(500 \mathrm{MHz}, \mathrm{CDCl}_{3}\right) \delta 7.31$ (d, $J=7.1$ $\mathrm{Hz}, \mathrm{Ar}-\mathrm{H}, 1 \mathrm{H}$ ), 7.18 (d, J=8.0 Hz, Ar-H, 1H), 7.15 (m, Ar-H, 3H), 6.92 $(\mathrm{t}, J=7.6 \mathrm{~Hz}, \mathrm{Ar}-\mathrm{H}, 1 \mathrm{H}), 6.77$ (d, J=1.4 Hz, Ar-H, 1H), 6.41 (d, J=7.1 $\mathrm{Hz}, \mathrm{Ar}-\mathrm{H}, 1 \mathrm{H}), 4.85$ (d, J=10.6 Hz, CH, 1H), 4.17 (dd, J=10.6, $6.9 \mathrm{~Hz}$, $\mathrm{CH}, 1 \mathrm{H}), 3.95(\mathrm{~d}, J=8.8 \mathrm{~Hz}, \mathrm{CH}, 1 \mathrm{H}), 3.50(\mathrm{~m}, \mathrm{CH}, 1 \mathrm{H}), 2.45$ (ddd, $\left.J=89.2,16.6,7.4 \mathrm{~Hz}, \mathrm{CH}_{2}, 2 \mathrm{H}\right), 1.09$ (t, $J=7.4 \mathrm{~Hz}, \mathrm{CH}_{3}, 3 \mathrm{H}$ ); MS (ESI): $397[\mathrm{M}+\mathrm{H}]^{+}$. Anal. Calcd for $\mathrm{C}_{21} \mathrm{H}_{17} \mathrm{ClN}_{2} \mathrm{O}_{4}: \mathrm{C}, 63.56 ; \mathrm{H}, 4.32 ; \mathrm{N}, 7.06$; Found: C, 63.59; H, 4.40; N, 7.08.

\section{General method for the synthesis of compounds 26-27 or 29-30}

Compounds were obtained by two steps. First, the obtained 11-13 $(0.47 \mathrm{mmol})$ were dissolved in methylene chloride $(30 \mathrm{~mL})$, and triethylamine $(0.4 \mathrm{~mL})$ was added, while stirring, a solution of bis(trichloromethyl)carbonate $(0.63 \mathrm{mmol})$ in dry methylene chloride $(10 \mathrm{~mL})$ was added in a period of $15 \mathrm{~min}$. The reaction mixture was stirred at $0^{\circ} \mathrm{C}$ for $30 \mathrm{~min}$ and solvent was removed to dryness. The residue was dissolved in dry methylene chloride $(10 \mathrm{~mL})$, and a solution of correspondingly amines $(2.88 \mathrm{mmol})$ in methylene chloride $(10 \mathrm{~mL})$ was added. The reaction was stirred for $20 \mathrm{~min}$ till it was done. The solvent was removed, extracted with methylene chloride and water, keep the organic, and washed with brine $(2 \times 20 \mathrm{~mL})$, dried with sodium sulfate. The solvent was removed to dryness and the obtained solid was crystallized with ethyl estate and petroleum ether to get a white solid 26-27 or 29-30.

2-(piperidin-1-ylcarbonyl)-2,3,3a,9b-tetrahydro-4Hspiro[chromeno[3,4-c]pyrrole-1,3'-indole]-2',4(1'H)-dione Yield: $28 \%$; M.P.: $118-120^{\circ} \mathrm{C}$; ${ }^{1} \mathrm{H}$ NMR $\left(500 \mathrm{MHz}, \mathrm{CDCl}_{3}\right) \delta 7.29$ (s, $\mathrm{OH}, 1 \mathrm{H}), 7.27(\mathrm{~m}, \mathrm{Ar}-\mathrm{H}, 2 \mathrm{H}), 7.12(\mathrm{t}, J=7.5 \mathrm{~Hz}, \operatorname{Ar}-\mathrm{H}, 1 \mathrm{H}), 7.06(\mathrm{~d}$, $J=8.2 \mathrm{~Hz}, \mathrm{Ar}-\mathrm{H}, 1 \mathrm{H}), 6.88(\mathrm{~s}, \mathrm{Ar}-\mathrm{H}, 1 \mathrm{H}), 6.82(\mathrm{t}, J=7.4 \mathrm{~Hz}, \mathrm{Ar}-\mathrm{H}, 1 \mathrm{H})$, $6.70(\mathrm{~d}, J=7.7 \mathrm{~Hz}, \operatorname{Ar}-\mathrm{H}, 1 \mathrm{H}), 6.24(\mathrm{~d}, J=7.3 \mathrm{~Hz}, \mathrm{Ar}-\mathrm{H}, 1 \mathrm{H}), 4.59$ (dd, $J=10.2,1.8 \mathrm{~Hz}, \mathrm{CH}, 1 \mathrm{H}), 4.34(\mathrm{~m}, \mathrm{CH}, 1 \mathrm{H}), 3.84(\mathrm{~d}, J=9.6 \mathrm{~Hz}, \mathrm{CH}, 1 \mathrm{H})$, $3.51(\mathrm{t}, J=7.9 \mathrm{~Hz}, \mathrm{CH}, 1 \mathrm{H}), 3.34\left(\mathrm{~m}, \mathrm{CH}_{2} \times 2,4 \mathrm{H}\right), 1.66\left(\mathrm{~m}, \mathrm{CH}_{2} \times 3,6 \mathrm{H}\right)$; MS (ESI): $418[\mathrm{M}+\mathrm{H}]^{+}$. Anal. Calcd for $\mathrm{C}_{24} \mathrm{H}_{23} \mathrm{~N}_{3} \mathrm{O}_{4}: \mathrm{C}, 69.05 ; \mathrm{H}, 5.55 ; \mathrm{N}$, 10.07; Found: C, 69.15; H, 5.59; N, 10.09 .

$N, N$-diethyl-2', 4-dioxo-1',2', 3 a , 9b-tetrahydro-4Hspiro[chromeno[3,4-c]pyrrole-1,3'-indole]-2(3H)-carboxamide (27): Yield: $34 \%$; M.P.: $220-224^{\circ} \mathrm{C}$; ${ }^{1} \mathrm{H}$ NMR $\left(500 \mathrm{MHz}, \mathrm{CDCl}_{3}\right) \delta 7.35$ (m, Ar-H, 3H), 7.20 (t, J=7.5 Hz, Ar-H, 1H), 7.10 (dd, $J=14.4,7.6 \mathrm{~Hz}$, Ar-H, 2H), 6.80 (t, J=7.5 Hz, Ar-H, 1H), 6.22 (d, J=7.3 Hz, Ar-H, $1 \mathrm{H}$ ), $4.84(\mathrm{~d}, J=15.6 \mathrm{~Hz}, \mathrm{CH}, 1 \mathrm{H}), 4.68(\mathrm{dd}, J=10.0,1.5 \mathrm{~Hz}, \mathrm{CH}, 1 \mathrm{H}), 4.33(\mathrm{~m}$, $\mathrm{CH}, 1 \mathrm{H}), 3.53(\mathrm{t}, J=7.9 \mathrm{~Hz}, \mathrm{CH}, 1 \mathrm{H}), 3.32\left(\mathrm{~m}, \mathrm{CH}_{2} \times 2,4 \mathrm{H}\right), 0.93(\mathrm{t}, J=7.1$ $\left.\mathrm{Hz}, \mathrm{CH}_{3} \times 2,6 \mathrm{H}\right)$; MS (ESI): 406[M+H] $]^{+}$. Anal. Calcd for $\mathrm{C}_{23} \mathrm{H}_{23} \mathrm{~N}_{3} \mathrm{O}_{4}: \mathrm{C}$, 68.13; H, 5.72; N, 10.36; Found: C, 68.19; H, 5.70; N, 10.38 .

6'-chloro-2-(piperidin-1-ylcarbonyl)-2,3,3a,9b-tetrahydro-4Hspiro[chromeno[3,4-c] pyrrole-1,3'-indole]-2',4(1'H)-dione Yield: $18 \%$; M.P.: $>250{ }^{\circ} \mathrm{C} ;{ }^{1} \mathrm{H}$ NMR $\left(500 \mathrm{MHz}, \mathrm{CDCl}_{3}\right) \delta 7.16$ (d, J=6.7 $\mathrm{Hz}, \mathrm{Ar}-\mathrm{H}, 1 \mathrm{H}), 7.04$ (t, J=7.5 Hz, Ar-H, 2H), 6.98 (d, J=2.0 Hz, Ar-H, $1 \mathrm{H}), 6.85(\mathrm{~m}, \mathrm{Ar}-\mathrm{H}, 1 \mathrm{H}), 6.72(\mathrm{dd}, J=8.0,2.0 \mathrm{~Hz}, \mathrm{Ar}-\mathrm{H}, 1 \mathrm{H}), 6.63(\mathrm{~d}$, $J=8.0 \mathrm{~Hz}, 1 \mathrm{H}), 6.07(\mathrm{~d}, J=8.2 \mathrm{~Hz}, 1 \mathrm{H}), 4.42(\mathrm{dd}, J=10.3,1.9 \mathrm{~Hz}, \mathrm{CH}$, $1 \mathrm{H}), 4.21(\mathrm{dd}, J=10.1,8.4 \mathrm{~Hz}, \mathrm{CH}, 1 \mathrm{H}), 3.70(\mathrm{~d}, J=9.6 \mathrm{~Hz}, \mathrm{CH}, 1 \mathrm{H})$, $3.46(\mathrm{~m}, 1 \mathrm{H}), 3.34\left(\mathrm{~m}, \mathrm{CH}_{2} \times 2,4 \mathrm{H}\right), 1.66\left(\mathrm{~m}, \mathrm{CH}_{2} \times 3,6 \mathrm{H}\right)$; MS (ESI): $452[\mathrm{M}+\mathrm{H}]^{+}$. Anal. Calcd for $\mathrm{C}_{24} \mathrm{H}_{22} \mathrm{ClN}_{3} \mathrm{O}_{4}: \mathrm{C}, 63.79 ; \mathrm{H}, 4.91 ; \mathrm{N}, 9.30$; Found: C, 63.89; H, 4.99; N, 9.31.

7-chloro-2-(piperidin-1-ylcarbonyl)-2,3,3a,9b-tetrahydro- $4 \mathrm{H}$ spiro[chromeno[3,4-c] pyrrole-1,3'-indole]-2',4(1'H)-dione $(30)$ : Yield: $30 \%$; M.P.: > $250{ }^{\circ} \mathrm{C}$; ${ }^{1} \mathrm{H}$ NMR $\left(500 \mathrm{MHz}, \mathrm{CDCl}_{3}\right) \delta 7.18(\mathrm{~d}, J=6.7$ $\mathrm{Hz}, \mathrm{Ar}-\mathrm{H}, 2 \mathrm{H}), 7.04$ (t, J=7.5 Hz, Ar-H, 1H), 6.99 (d, J=2.0 Hz, Ar-H, $1 \mathrm{H}), 6.85$ (s, Ar-H, 1H), 6.72 (dd, J=8.2, $2.0 \mathrm{~Hz}, \mathrm{Ar}-\mathrm{H}, 1 \mathrm{H}), 6.63$ (d, $J=8.0 \mathrm{~Hz}, \mathrm{Ar}-\mathrm{H}, 1 \mathrm{H}), 6.07$ (d, J=8.2 Hz, Ar-H, 1H), 4.48 (dd, $J=10.3,1.9$ $\mathrm{Hz}, \mathrm{CH}, 1 \mathrm{H}), 4.22(\mathrm{dd}, J=10.1,8.4 \mathrm{~Hz}, \mathrm{CH}, 1 \mathrm{H}), 3.72(\mathrm{~d}, J=9.6 \mathrm{~Hz}, \mathrm{CH}$, $1 \mathrm{H}), 3.46(\mathrm{~m}, \mathrm{CH}, 1 \mathrm{H}), 3.28\left(\mathrm{~m}, \mathrm{CH}_{2} \times 2,4 \mathrm{H}\right), 1.58\left(\mathrm{~m}, \mathrm{CH}_{3} \times 2,6 \mathrm{H}\right)$; MS (ESI): $452[\mathrm{M}+\mathrm{H}]^{+}$. Anal. Calcd for $\mathrm{C}_{24} \mathrm{H}_{22} \mathrm{ClN}_{3} \mathrm{O}_{4}: \mathrm{C}, 63.79 ; \mathrm{H}, 4.91 ; \mathrm{N}$, 9.30; Found: C, 63.81; H, 4.89; N, 9.27.

\section{General method for the synthesis of compounds 31-43}

25-30 (0.16 mmol) was dissolved in THF $(6 \mathrm{~mL})$, corresponding amine $(0.48 \mathrm{mmol})$ was added, after refluxing for min, the solvent was removed by rotary evaporation and the residue was extracted by ethyl estate and water, the organic layer was kept and washed with brine $(3 \times 10 \mathrm{~mL})$, dried with sodium sulfate, then removed the solvent, the obtained solid was recrystallized in ethyl estate/petroleum ether and get a white solid 31-43.

3 ' - ( 2 - hydroxyphenyl) - 2 - oxo- 1 ' - propionyl - 1, 2 dihydrospiro[indole-3,2'-pyrrolidine]-4'-carboxamide (31): Yield: 85\%; M.P.: $124-126{ }^{\circ} \mathrm{C} ;{ }^{1} \mathrm{H}$ NMR $\left(500 \mathrm{MHz}, \mathrm{CDCl}_{3}\right) \delta 7.24$ (s, $\mathrm{NH}_{2}$, 2H), $7.12(\mathrm{t}, J=7.6 \mathrm{~Hz}, \mathrm{Ar}-\mathrm{H}, 1 \mathrm{H}), 7.18(\mathrm{~m}, \mathrm{Ar}-\mathrm{H}, 2 \mathrm{H}), 6.86(\mathrm{~m}, \mathrm{Ar}-\mathrm{H}$, $4 \mathrm{H}), 6.74(\mathrm{~d}, J=7.7 \mathrm{~Hz}, \mathrm{Ar}-\mathrm{H}, 1 \mathrm{H}), 6.36(\mathrm{~m}, \mathrm{Ar}-\mathrm{H}, 1 \mathrm{H}), 4.81$ (d, J=10.4 
$\mathrm{Hz}, \mathrm{CH}, 1 \mathrm{H}), 4.18(\mathrm{dd}, J=10.6,6.9 \mathrm{~Hz}, \mathrm{CH}, 1 \mathrm{H}), 3.96(\mathrm{~d}, J=8.8 \mathrm{~Hz}, \mathrm{CH}$, $1 \mathrm{H}), 3.48(\mathrm{~m}, \mathrm{CH}, 1 \mathrm{H}), 2.51(\mathrm{dd}, J=16.6,7.4 \mathrm{~Hz}, \mathrm{CH}, 1 \mathrm{H}), 2.33(\mathrm{dd}$, $J=16.6,7.4 \mathrm{~Hz}, \mathrm{CH}, 1 \mathrm{H}$ ), 1.08 (dd, $J=9.4,5.4 \mathrm{~Hz}, \mathrm{CH}_{3}, 3 \mathrm{H}$ ); MS (ESI): $380[\mathrm{M}+\mathrm{H}]^{+}$. Anal. Calcd for $\mathrm{C}_{21} \mathrm{H}_{21} \mathrm{~N}_{3} \mathrm{O}_{4}: \mathrm{C}, 66.48 ; \mathrm{H}, 5.58 ; \mathrm{N}, 11.08$; Found: $\mathrm{C}, 66.44 ; \mathrm{H}, 5.56 ; \mathrm{N}, 11.18$.

3' - (2-hyd roxyphenyl) -4' - (morpholin-4-ylcarbonyl) - 1' propionylspiro[indole-3,2'-pyrrolidin]-2(1H)-one (32): Yield: $78 \%$; M.P.: $131-133^{\circ} \mathrm{C} ;{ }^{1} \mathrm{H}$ NMR $\left(500 \mathrm{MHz}, \mathrm{CDCl}_{3}\right) \delta 7.26(\mathrm{~m}, \mathrm{Ar}-\mathrm{H}, 2 \mathrm{H})$, $7.12(\mathrm{t}, J=7.5 \mathrm{~Hz}, \mathrm{Ar}-\mathrm{H}, 1 \mathrm{H}), 7.08(\mathrm{~m}, \mathrm{Ar}-\mathrm{H}, 2 \mathrm{H}), 6.86(\mathrm{td}, J=7.5,1.0$ $\mathrm{Hz}, \mathrm{Ar}-\mathrm{H}, 1 \mathrm{H}), 6.74(\mathrm{~d}, J=7.7 \mathrm{~Hz}, \mathrm{Ar}-\mathrm{H}, 1 \mathrm{H}), 6.34$ (m, Ar-H, $1 \mathrm{H}), 4.85$ (d, $J=10.4 \mathrm{~Hz}, \mathrm{CH}, 1 \mathrm{H}), 4.18(\mathrm{dd}, J=10.6,6.9 \mathrm{~Hz}, \mathrm{CH}, 1 \mathrm{H}), 3.70(\mathrm{~m}$, $\left.\mathrm{CH}_{2} \times 3,6 \mathrm{H}\right), 3.53\left(\mathrm{~m}, \mathrm{CH}_{2} \times 2,4 \mathrm{H}\right), 2.53(\mathrm{dd}, J=16.6,7.4 \mathrm{~Hz}, \mathrm{CH}, 1 \mathrm{H})$, 2.35 (dd, $J=16.6,7.4 \mathrm{~Hz}, \mathrm{CH}, 1 \mathrm{H}$ ), 1.08 (dd, $J=9.4,5.4 \mathrm{~Hz}, \mathrm{CH}_{3}, 3 \mathrm{H}$ ); MS (ESI): $450[\mathrm{M}+\mathrm{H}]^{+}$. Anal. Calcd for $\mathrm{C}_{25} \mathrm{H}_{27} \mathrm{~N}_{3} \mathrm{O}_{5}: \mathrm{C}, 66.80 ; \mathrm{H}, 6.05 ; \mathrm{N}$, 9.35; Found: C, 66.82; H, 6.07; N, 9.25.

3'-(2-hydroxyphenyl)-2-oxo-1'-(piperidin-1-ylcarbonyl)-1,2dihydrospiro[indole-3,2'-pyrrolidine]-4'-carboxamide (33): Yield: 85\%; M.P.: $195-198^{\circ} \mathrm{C} ;{ }^{1} \mathrm{H}$ NMR $(500 \mathrm{MHz}, \mathrm{MeOD}) \delta 7.45$ (d, $J=7.1$ $\mathrm{Hz}, \mathrm{Ar}-\mathrm{H}, 1 \mathrm{H}), 6.98(\mathrm{dd}, J=7.9,6.9 \mathrm{~Hz}, \mathrm{Ar}-\mathrm{H}, 2 \mathrm{H}), 6.82(\mathrm{t}, J=7.0 \mathrm{~Hz}$, Ar-H, 1H), 6.73 (d, J=7.6 Hz, Ar-H, 1H), 6.48 (m, Ar-H, 2H), 5.94 (d, $J=7.4 \mathrm{~Hz}, \mathrm{Ar}-\mathrm{H}, 1 \mathrm{H}), 4.62(\mathrm{t}, J=10.0 \mathrm{~Hz}, \mathrm{CH}, 1 \mathrm{H}), 4.43$ (dd, J=17.9, 9.8 $\mathrm{Hz}, \mathrm{CH}, 1 \mathrm{H}), 4.36(\mathrm{~d}, J=8.0 \mathrm{~Hz}, \mathrm{CH}, 1 \mathrm{H}), 3.91(\mathrm{t}, J=9.7 \mathrm{~Hz}, \mathrm{CH}, 1 \mathrm{H})$, $3.40\left(\mathrm{~m}, \mathrm{CH}_{2}, 2 \mathrm{H}\right), 3.30\left(\mathrm{~m}, \mathrm{CH}_{2}, 2 \mathrm{H}\right), 1.58\left(\mathrm{~d}, \mathrm{~J}=54.8 \mathrm{~Hz}, \mathrm{CH}_{2}, 6 \mathrm{H}\right)$; MS (ESI): 435[M+H] ${ }^{+}$. Anal. Calcd for C24H26N4O4: C, 66.34; H, 6.03; N, 12.89; Found: C, 66.42; H, 6.09; N, 12.87.

3'-(2-hydroxyphenyl) - 4' - (morpholin-4-ylcarbonyl) - 1'(piperidin-1-ylcarbonyl)spiro[indole-3,2'-pyrrolidin]-2(1H)-one (34): Yield: 70\%; M.P.: $154-156^{\circ} \mathrm{C} ;{ }^{1} \mathrm{H}$ NMR $\left(500 \mathrm{MHz}, \mathrm{CDCl}_{3}\right) \delta 8.07$ (s, OH, 1H), 7.36 (d, J=7.3 Hz, Ar-H, 1H), 7.08 (dd, $J=15.3,7.7 \mathrm{~Hz}, \mathrm{Ar}-$ H, 2H), 7.00 (t, J=7.6 Hz, Ar-H, 2H), 6.68 (dd, J=19.5, 7.8 Hz, Ar-H, 2H), $6.56(\mathrm{~d}, J=7.6 \mathrm{~Hz}, \mathrm{Ar}-\mathrm{H}, 1 \mathrm{H}), 4.78(\mathrm{dd}, J=19.8,9.0 \mathrm{~Hz}, \mathrm{CH}, 1 \mathrm{H})$, 4.45 (d, J=11.9 Hz, CH, 1H), 4.00 (dq, J=17.5, $8.9 \mathrm{~Hz}, \mathrm{CH}, 2 \mathrm{H}), 3.70$ (ddd, $J=15.5,8.8,5.2 \mathrm{~Hz}, \mathrm{CH}, 4 \mathrm{H}), 3.59$ (dd, $J=10.2,5.1 \mathrm{~Hz}, \mathrm{CH}, 2 \mathrm{H}$ ), $3.42(\mathrm{~m}, \mathrm{CH}, 2 \mathrm{H}), 3.33(\mathrm{~m}, \mathrm{CH}, 4 \mathrm{H}), 2.91(\mathrm{~m}, \mathrm{CH}, 2 \mathrm{H}), 1.66(\mathrm{~m}, \mathrm{CH}$, $4 \mathrm{H}$ ); MS (ESI): 505[M+H] $]^{+}$. Anal. Calcd for C28H32N4O5: C, 66.65; H, 6.39; N, 11.10; Found: C, 66.66; H, 6.37; N, 11.12.

3'-(2-hydroxyphenyl)-4'-[(4-methylpiperazin-1-yl)carbonyl]-1'(piperidin-1-ylcarbonyl)spiro[indole-3,2'-pyrrolidin]-2(1H)-one (35): Yield: $70 \%$; M.P.: $170-173^{\circ} \mathrm{C}$; ${ }^{1} \mathrm{H} \mathrm{NMR}\left(500 \mathrm{MHz}, \mathrm{CDCl}_{3}\right) \delta 7.50$ (s, OH, 1H), 7.35 (d, J=7.3 Hz, Ar-H, 1H), 7.17 (d, J=6.4 Hz, Ar-H, 1H), $7.10(\mathrm{t}, J=7.7 \mathrm{~Hz}, \mathrm{Ar}-\mathrm{H}, 1 \mathrm{H}), 7.00(\mathrm{t}, J=7.6 \mathrm{~Hz}, \mathrm{Ar}-\mathrm{H}, 2 \mathrm{H}), 6.72(\mathrm{t}, J=7.6$ $\mathrm{Hz}, \mathrm{Ar}-\mathrm{H}, 1 \mathrm{H}), 6.67$ (d, J=7.9 Hz, Ar-H, 1H), 6.58 (d, J=7.7 Hz, Ar-H, $1 \mathrm{H}), 4.72(\mathrm{~d}, J=10.5 \mathrm{~Hz}, \mathrm{CH}, 1 \mathrm{H}), 4.48(\mathrm{~d}, J=11.9 \mathrm{~Hz}, \mathrm{CH}, 1 \mathrm{H}), 3.98(\mathrm{dt}$, $J=18.3,9.0 \mathrm{~Hz}, \mathrm{CH}, 2 \mathrm{H}), 3.61(\mathrm{~m}, \mathrm{CH}, 2 \mathrm{H}), 3.25(\mathrm{dt}, J=19.7,11.9 \mathrm{~Hz}$, $\mathrm{CH}, 4 \mathrm{H}), 2.37(\mathrm{~d}, J=6.4 \mathrm{~Hz}, \mathrm{CH}, 2 \mathrm{H}), 2.24\left(\mathrm{~s}, \mathrm{CH}_{3}, 3 \mathrm{H}\right), 2.16(\mathrm{~m}, \mathrm{CH}$, $4 \mathrm{H}), 1.54(\mathrm{~d}, J=36.8 \mathrm{~Hz}, \mathrm{CH}, 6 \mathrm{H})$; MS (ESI): $518[\mathrm{M}+\mathrm{H}]^{+}$. Anal. Calcd for $\mathrm{C}_{29} \mathrm{H}_{35} \mathrm{~N}_{5} \mathrm{O}_{4}$ : C, 67.29; $\mathrm{H}, 6.82$; N, 13.53; Found: C, 67.31; H, 6.84; $\mathrm{N}, 13.55$.

$\mathrm{N}$-(2-hydroxyethyl)-3'-(2-hydroxyphenyl)-2-oxo-1'-(piperidin1-ylcarbonyl)-1,2-dihydrospiro[indole-3,2'-pyrrolidine]-4' carboxamide (36): Yield: $58 \%$; M.P.: $220-222^{\circ} \mathrm{C}$; ${ }^{1} \mathrm{H}$ NMR $(500 \mathrm{MHz}$, $\left.\mathrm{CDCl}_{3}\right) \delta 7.36(\mathrm{~d}, J=7.3 \mathrm{~Hz}, \mathrm{Ar}-\mathrm{H}, 1 \mathrm{H}), 7.13(\mathrm{~d}, J=7.4 \mathrm{~Hz}, \mathrm{Ar}-\mathrm{H}, 1 \mathrm{H})$, 7.09 (m, Ar-H, 1H), 6.88 (s, Ar-H, 1H), 6.77 (m, Ar-H, 1H), 6.56 (d, $J=41.5 \mathrm{~Hz}, \mathrm{Ar}-\mathrm{H}, 1 \mathrm{H}), 3.46(\mathrm{~m}, \mathrm{CH}, 2 \mathrm{H}), 3.38(\mathrm{~m}, \mathrm{CH}, 5 \mathrm{H}), 2.65(\mathrm{~m}$, $\mathrm{CH}, 2 \mathrm{H}), 1.67$ (m, CH, 4H), 1.27 (m, CH, 2H); MS (ESI): 479[M+H] $]^{+}$. Anal. Calcd for $\mathrm{C}_{26} \mathrm{H}_{30} \mathrm{~N}_{4} \mathrm{O}_{5}$ : C, 65.26; H, 6.32; N, 11.71; Found: C, 65.28; H, 6.30; N, 11.73 .
$N, N$-diethyl-3' - (2-hydroxyphenyl) - 4' - (morpholin-4ylcarbonyl)-2-oxo-1,2-dihydro-1' $H$-spiro[indole-3,2'-pyrrolidine]1'-carboxamide (37): Yield: $60 \%$; M.P.: $159-166^{\circ} \mathrm{C}$; ${ }^{1} \mathrm{H}$ NMR $(500$ $\left.\mathrm{MHz}, \mathrm{CDCl}_{3}\right) \delta 7.37$ (t, J=7.0 Hz, Ar-H, 1H), 7.16 (m, Ar-H, 2H), 7.03 (dd, J=13.2, 7.2 Hz, Ar-H, 2H), 6.77 (m, Ar-H, 2H), 6.60 (d, J=7.7 Hz, Ar-H, 1H), 4.74 (d, J=10.0 Hz, CH, 1H), 4.46 (dd, J=11.8, $5.2 \mathrm{~Hz}, \mathrm{CH}$, $1 \mathrm{H}), 3.99\left(\mathrm{dd}, J=17.3,9.0 \mathrm{~Hz}, \mathrm{CH}_{2}, 2 \mathrm{H}\right), 3.76\left(\mathrm{~m}, \mathrm{CH}_{2} \times 3,6 \mathrm{H}\right), 3.48$ $\left(\mathrm{m}, \mathrm{CH}_{2} \times 3,6 \mathrm{H}\right), 3.16\left(\mathrm{dd}, J=14.3,7.2 \mathrm{~Hz}, \mathrm{CH}_{2}, 2 \mathrm{H}\right), 1.12(\mathrm{t}, J=7.1 \mathrm{~Hz}$, $\left.\mathrm{CH}_{3} \times 2,6 \mathrm{H}\right)$; MS (ESI): $493[\mathrm{M}+\mathrm{H}]^{+}$. Anal. Calcd for $\mathrm{C}_{27} \mathrm{H}_{32} \mathrm{~N}_{4} \mathrm{O}_{5}: \mathrm{C}$, 65.84; H, 6.55; N, 11.37; Found: C, 65.86; H, 6.59; N, 11.33 .

6-chloro-3'-(2-hydroxyphenyl)-2-oxo-1'-propionyl-1,2dihydrospiro[indole-3, $2^{\prime}$-pyrrolidine]-4'-carboxamide (38): Yield: 89\%; M.P.: $124-126^{\circ} \mathrm{C} ;{ }^{1} \mathrm{H}$ NMR $\left(500 \mathrm{MHz}, \mathrm{CDCl}_{3}\right) 7.48(\mathrm{~d}, J=8.0 \mathrm{~Hz}$, Ar-H, 1H), 7.30 (m, Ar-H, 2H), 7.00 (dd, $J=8.3,2.1 \mathrm{~Hz}, \mathrm{Ar}-\mathrm{H}, 2 \mathrm{H}), 6.76$ (d, $J=1.8 \mathrm{~Hz}, \mathrm{Ar}-\mathrm{H}, 1 \mathrm{H}), 6.31(\mathrm{~d}, J=8.3 \mathrm{~Hz}, \mathrm{Ar}-\mathrm{H}, 1 \mathrm{H}), 4.15$ (m, CH, $1 \mathrm{H}), 3.98$ (d, J=10.9 Hz, CH, 1H), 3.89 (s, CH, 1H), 3.79 (t, J=9.2 Hz, $\mathrm{CH}, 1 \mathrm{H}), 3.46(\mathrm{dd}, J=9.3,4.4 \mathrm{~Hz}, \mathrm{CH}, 1 \mathrm{H}), 3.17(\mathrm{~d}, J=5.0 \mathrm{~Hz}, \mathrm{CH}, 1 \mathrm{H})$, 2.53 (dd, J=16.6, 7.4 Hz, CH, CH, 1H), 2.35 (dd, J=16.6, 7.4 Hz, CH, $1 \mathrm{H}), 1.13\left(\mathrm{t}, J=7.5 \mathrm{~Hz}, \mathrm{CH}_{3}, 3 \mathrm{H}\right)$; MS (ESI): 414[M+H] $]^{+}$. Anal. Calcd for $\mathrm{C}_{21} \mathrm{H}_{20} \mathrm{ClN}_{3} \mathrm{O}_{4}$ : C, 60.95; H, 4.87; N, 10.15; Found: C, 60.85; H, 4.90; $\mathrm{N}, 10.21$.

6-chloro-3'-(2-hydroxyphenyl)-4'-(morpholin-4-ylcarbonyl)-1'propionylspiro[indole-3,2'-pyrrolidin]-2(1H)-one (39): Yield: $56 \%$; M.P.: $179-184^{\circ} \mathrm{C} ;{ }^{1} \mathrm{H}$ NMR (500 MHz, MeOD) $\delta 7.26(\mathrm{~m}, \mathrm{Ar}-\mathrm{H}, 1 \mathrm{H})$, 7.01 (d, J=1.8 Hz, Ar-H, 2H), 6.74 (m, Ar-H, 2H), 6.65 (m, Ar-H, 2H), $4.70(\mathrm{~d}, J=9.0 \mathrm{~Hz}, \mathrm{CH}, 1 \mathrm{H}), 4.28(\mathrm{dt}, J=7.7,6.0 \mathrm{~Hz}, \mathrm{CH}, 1 \mathrm{H}), 4.20$ (dd, $J=16.8,8.4 \mathrm{~Hz}, \mathrm{CH}, 1 \mathrm{H}), 3.75\left(\mathrm{~m}, \mathrm{CH}_{2}, 2 \mathrm{H}\right), 3.55\left(\mathrm{~m}, \mathrm{CH}_{2}, 2 \mathrm{H}\right), 3.33$ (dt, J=3.1, $\left.1.6 \mathrm{~Hz}, \mathrm{CH}_{2}, 2 \mathrm{H}\right), 3.27\left(\mathrm{~m}, \mathrm{CH}_{2}, 2 \mathrm{H}\right), 2.49$ (d, J=7.4 Hz, $\mathrm{CH}_{2}$, 2H), 1.06 (t, J=7.5 Hz, CH, 3H); MS (ESI): 497[M+H] ${ }^{+}$. Anal. Calcd for $\mathrm{C}_{25} \mathrm{H}_{26} \mathrm{ClN}_{3} \mathrm{O}_{5}$ : C, 62.05; H, 5.42; N, 8.68; Found: C, 62.09; H, 5.46; N, 8.72 .

6-chloro-3'-(2-hydroxyphenyl)-2-oxo-1'-(piperidin-1ylcarbonyl) - 1,2-dihydrospiro[indole-3,2'-pyrrolidine]-4'carboxamide (40): Yield: 70\%; M.P.: $206-209^{\circ} \mathrm{C} ;{ }^{1} \mathrm{H}$ NMR $(500 \mathrm{MHz}$, DMSO) $\delta 10.29(\mathrm{~s}, \mathrm{NH}, 1 \mathrm{H}), 8.94(\mathrm{~s}, \mathrm{OH}, 1 \mathrm{H}), 7.36(\mathrm{~m}, \mathrm{Ar}-\mathrm{H}, 2 \mathrm{H}), 6.96$ $(\mathrm{t}, J=7.7 \mathrm{~Hz}, \mathrm{Ar}-\mathrm{H}, 1 \mathrm{H}), 6.82(\mathrm{~m}, \mathrm{Ar}-\mathrm{H}, 1 \mathrm{H}), 6.62(\mathrm{~d}, J=1.9 \mathrm{~Hz}, \mathrm{Ar}-\mathrm{H}$, $1 \mathrm{H}), 6.50$ (d, J=7.8 Hz, Ar-H, 1H), 6.40 (dd, J=8.0, $1.8 \mathrm{~Hz}, \mathrm{Ar}-\mathrm{H}, 1 \mathrm{H})$, $4.48(\mathrm{t}, J=9.7 \mathrm{~Hz}, \mathrm{CH}, 1 \mathrm{H}), 4.25(\mathrm{~m}, \mathrm{CH}, 2 \mathrm{H}), 3.65(\mathrm{t}, J=9.7 \mathrm{~Hz}, \mathrm{CH}$, $1 \mathrm{H}), 3.15$ (dd, $\left.J=41.6,9.4 \mathrm{~Hz}, \mathrm{CH}_{2} \times 2,4 \mathrm{H}\right), 1.46$ (d, J=52.5 Hz, $\mathrm{CH}_{3} \times 2$, $6 \mathrm{H})$; MS (ESI): $499[\mathrm{M}+\mathrm{H}]^{+}$. Anal. Calcd for $\mathrm{C}_{26} \mathrm{H}_{31} \mathrm{ClN}_{4} \mathrm{O}_{4}: \mathrm{C}, 62.58 ; \mathrm{H}$, 6.26; N, 11.23; Found: C, 62.62; H, 6.28; N, 11.25.

6-chloro-3'-(2-hydroxyphenyl)-4'-[(4-methylpiperazin-1-yl) carbonyl]-1'-(piperidin-1-ylcarbonyl)spiro[indole-3,2'-pyrrolidin]2(1H)-one (41): Yield: M.P.: $168-170^{\circ} \mathrm{C} ;{ }^{1} \mathrm{H}$ NMR (500 MHz, $\left.\mathrm{CDCl}_{3}\right)$ $\delta 7.27$ (m, Ar-H, 2H), $7.01(\mathrm{~m}, \mathrm{Ar}-\mathrm{H}, 2 \mathrm{H}), 6.75(\mathrm{~m}, \mathrm{Ar}-\mathrm{H}, 1 \mathrm{H}), 6.60$ (d, J=7.7 Hz, Ar-H, 1H), 6.54 (s, Ar-H, 1H), 4.66 (s, CH, 1H), 4.55 (d, $J=12.1 \mathrm{~Hz}, \mathrm{CH}, 1 \mathrm{H}), 3.96(\mathrm{dd}, J=12.4,8.9 \mathrm{~Hz}, \mathrm{CH}, 2 \mathrm{H}), 3.63\left(\mathrm{~m}, \mathrm{CH}_{2}\right.$, $2 \mathrm{H}), 3.24\left(\mathrm{dd}, J=28.4,9.4 \mathrm{~Hz}, \mathrm{CH}_{2}, 4 \mathrm{H}\right), 2.33\left(\mathrm{~m}, \mathrm{CH}_{2}, 2 \mathrm{H}\right), 2.23(\mathrm{~s}$, $\left.\mathrm{CH}_{3}, 3 \mathrm{H}\right), 2.17\left(\mathrm{~m}, \mathrm{CH}_{2}, 4 \mathrm{H}\right), 1.54\left(\mathrm{~d}, J=39.5 \mathrm{~Hz}, \mathrm{CH}_{2}, 6 \mathrm{H}\right)$; MS(ESI): $552[\mathrm{M}+\mathrm{H}]^{+}$. Anal. Calcd for $\mathrm{C}_{29} \mathrm{H}_{34} \mathrm{ClN}_{5} \mathrm{O}_{4}$ : C, 63.09; H, 6.21; N, 12.69; Found: C, 63.15; H, 6.25; N, 12.73 .

3'-(4-chloro-2-hydroxyphenyl)-4'-(morpholin-4-ylcarbonyl)-1'(piperidin-1-ylcarbonyl)spiro[indole-3,2'-pyrrolidin]-2(1H)-one (42): Yield: 78\%; M.P.: $178-180^{\circ} \mathrm{C}$; ${ }^{1} \mathrm{H}$ NMR $(500 \mathrm{MHz}, \mathrm{MeOD}) \delta 7.41$ (m, Ar-H, 1H), $7.16(\mathrm{~s}, \mathrm{Ar}-\mathrm{H}, 1 \mathrm{H}), 7.11(\mathrm{t}, J=7.6 \mathrm{~Hz}, \mathrm{Ar}-\mathrm{H}, 1 \mathrm{H}), 6.98(\mathrm{t}$, $J=7.5 \mathrm{~Hz}, \mathrm{Ar}-\mathrm{H}, 1 \mathrm{H}), 6.66(\mathrm{dd}, J=8.4,2.1 \mathrm{~Hz}, \mathrm{Ar}-\mathrm{H}, 1 \mathrm{H}), 6.61$ (d, $J=7.7$ $\mathrm{Hz}, \mathrm{Ar}-\mathrm{H}, 1 \mathrm{H}), 6.51(\mathrm{~d}, J=2.1 \mathrm{~Hz}, \mathrm{Ar}-\mathrm{H}, 1 \mathrm{H}), 4.68(\mathrm{~d}, J=12.2 \mathrm{~Hz}, \mathrm{CH}$, $1 \mathrm{H}), 4.62(\mathrm{~d}, J=8.7 \mathrm{~Hz}, \mathrm{CH}, 1 \mathrm{H}), 4.04(\mathrm{~m}, \mathrm{CH}, 2 \mathrm{H}), 3.80\left(\mathrm{~m}, \mathrm{CH}_{2} \times 2\right.$, $4 \mathrm{H}), 3.55\left(\mathrm{~m}, \mathrm{CH}_{2} \times 2,4 \mathrm{H}\right), 3.24\left(\mathrm{dd}, J=20.8,14.2 \mathrm{~Hz}, \mathrm{CH}_{2} \times 2,4 \mathrm{H}\right), 1.67$ 
Citation: Hong L, Tong J, Yu G, Hu C (2017) Synthesis and Anti-Cancer Evaluation of Spiro-indolinone Derivatives. Med Chem (Los Angeles) 7: 846852. doi: $10.4172 / 2161-0444.1000440$

(m, $\left.\mathrm{CH}_{2} \times 3,6 \mathrm{H}\right) ; \mathrm{MS}(\mathrm{ESI}): 469[\mathrm{M}+\mathrm{H}]^{+}$. Anal. Calcd for $\mathrm{C}_{28} \mathrm{H}_{31} \mathrm{ClN}_{4} \mathrm{O}_{5}$ : C, 62.39; H, 5.80; N, 10.39; Found: C, 62.41; H, 5.77; N, 10.43 .

3'-(4-chloro-2-hydroxyphenyl)-4'-[(4-methylpiperazin-1-yl) carbonyl]-1'-(piperidin-1-ylcarbonyl)spiro[indole-3,2'-pyrrolidin]2(1H)-one (43): Yield: $68 \%$; M.P.: $209-211^{\circ} \mathrm{C} ;{ }^{1} \mathrm{H}$ NMR $(500 \mathrm{MHz}$, $\left.\mathrm{CDCl}_{3}\right) \delta 7.27$ (m, Ar-H, 2H), 7.01 (m, Ar-H, 2H), $6.75(\mathrm{~m}, \mathrm{Ar}-\mathrm{H}, 1 \mathrm{H})$, $6.60(\mathrm{~d}, J=7.7 \mathrm{~Hz}, \mathrm{Ar}-\mathrm{H}, 1 \mathrm{H}), 6.54(\mathrm{~s}, \mathrm{Ar}-\mathrm{H}, 1 \mathrm{H}), 4.66$ (s, CH, 1H), 4.55 (d, J=12.1 Hz, CH, $1 \mathrm{H}$ ), 3.96 (dd, $J=12.4,8.9 \mathrm{~Hz}, \mathrm{CH}, 2 \mathrm{H}), 3.63(\mathrm{~m}, \mathrm{CH}$, $2 \mathrm{H}), 3.24(\mathrm{dd}, J=28.4,9.4 \mathrm{~Hz}, \mathrm{CH}, 4 \mathrm{H}), 2.23\left(\mathrm{~s}, \mathrm{CH}_{3}, 3 \mathrm{H}\right), 2.17(\mathrm{~m}, \mathrm{CH}$, $4 \mathrm{H}), 1.54(\mathrm{~d}, J=39.5 \mathrm{~Hz}, \mathrm{CH}, 8 \mathrm{H})$; MS (ESI): 552[M+H] ${ }^{+}$. Anal. Calcd for C29H34ClN5O4: C, 63.09; H, 6.21; N, 12.69; Found: C, 63.13; H, $6.25 ; \mathrm{N}, 12.72$.

\section{Results and Discussion}

Based on the inhibition data of p53-MDM2 binding and the in vitro antitumor activity of the compounds in Table 1, the following conclusions can be drawn:
Some of the compounds showed moderate to strong inhibition of p53-MDM2 binding. The activity of lactone ring - opening compounds (14-18, 31-43) was significantly higher than that of lactone compounds (9-10, 25-30). Among them, the inhibitory activity of the indole6-phenylcyclopropene derivatives $(\mathbf{1 6 - 1 8}, \mathbf{3 8 - 4 3})$ on p53-MDM2 binding was not superior to the non-chlorinated derivatives (14-15, 31-37). From the tumor cell proliferation inhibitory activity point of view, the introductions of chlorine atoms help to improve activity. The activity of the N-piperidinecarboxyl-substituted compounds (40-43) on the pyrrole ring is generally higher than that of the N-propionylsubstituted compounds (40-43) in the presence of the chlorine atom, Compounds (38-39) and N-methyl substituted compounds (16-18). The obtained compounds showed weak inhibitory activity against wildtype p53-expressing cell lines HCT116 and A549, as well as that against p53-deficient PC3 cell lines, and some of the compounds exhibited excellent effects on the p53 mutant SW620 cell line (28, 42, $\mathrm{IC}_{50}<0.08$ $\mu \mathrm{M})$, suggesting that the action of these compounds may be related to

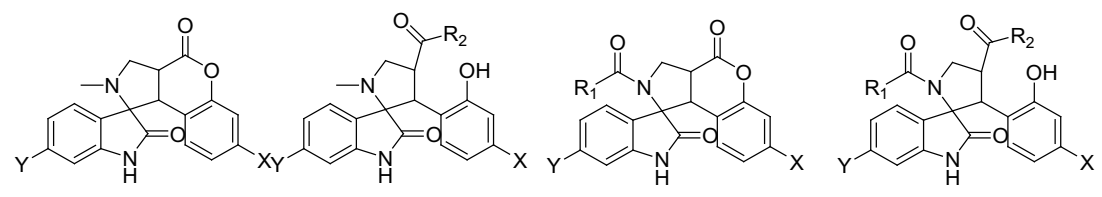

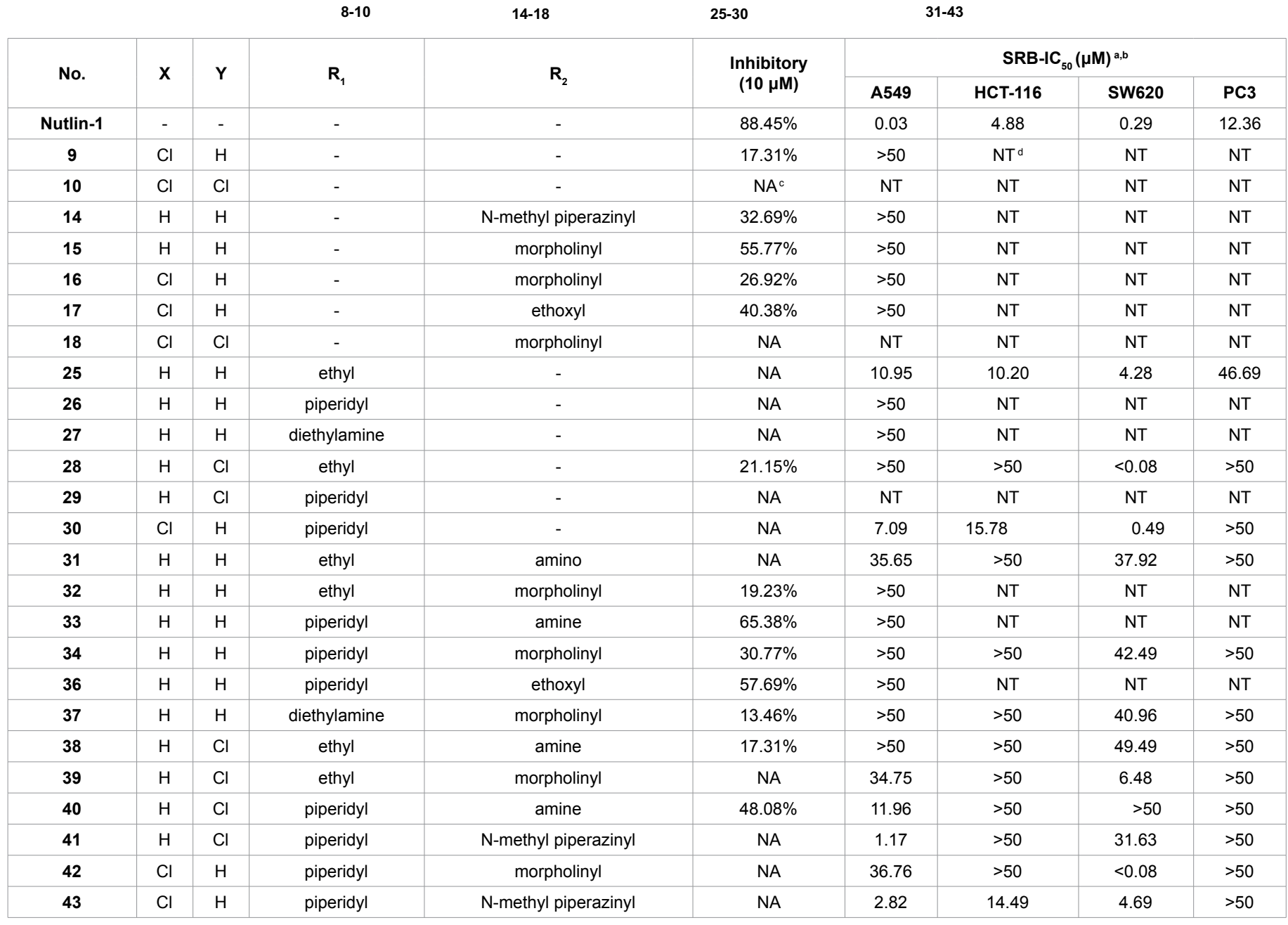

aValues are means of three experiments; ${ }^{\mathrm{D} N A}$, No activity; ${ }^{\mathrm{N} T}$, not tested

Table 1: The inhibitory of p53-MDM2 and anti-cancer activities of spiro-indolinone derivatives 
other targets on the p53 pathway, which is worthy of further study on the treatment of p53 mutant tumors.

\section{Conclusions}

A series of spiro-indolin-2-one compounds have been designed and synthesized based on the known spiro-indolin-2-ones and MDM2 proteins as p53-MDM2 binding inhibitors, 27 novel molecules were synthesized and their structures were confirmed by $1 \mathrm{H}$ NMR, MS and elementary analysis. The inhibitory activity of p53-MDM2 binding assay showed that some of the compounds had moderate inhibitory activity but showed weaker activity on wild-type p53 tumor cell lines. These compounds have potent inhibitory activity on p53 mutant cell line SW620 and may be involved in other p53-related signalling pathways or activation of $\mathrm{p} 53$ function, which is worth further study.

\section{Acknowledgements}

This study was financially supported by Natural Science Foundation of China (No. 81502926) and Zhejiang Provincial Natural Science Foundation (LQ13H300001).

\section{References}

1. Canner JA, Sobo M, Ball S, Hutzen B, DeAngelis S, et al. (2009) MI-63: a novel small-molecule inhibitor targets MDM2 and induces apoptosis in embryonal and alveolar rhabdomyosarcoma cells with wild-type p53. British Journal of Cancer 101: 774-781

2. Azmi AS, Aboukameel A, Banerjee S, Wang Z, Mohammad M, et al. (2010) MDM2 inhibitor MI-319 in combination with cisplatin is an effective treatment for pancreatic cancer independent of p53 function. Eur J Cancer 46: 1122-1131.
3. Zhao Y, Aguilar A, Bernard D, Wang S (2015) Small-molecule inhibitors of the MDM2-p53 protein-protein interaction (MDM2 Inhibitors) in clinical trials for cancer treatment. J Med Chem 58: 1038-1052.

4. Wang S, Jiang Y, Wu S, Dong G (2016) Meeting Organocatalysis with Drug Discovery: Asymmetric Synthesis of 3,3'-Spirooxindoles Fused with Tetrahydrothiopyrans as Novel p53-MDM2 Inhibitors. Org Lett 18: 1028-1031.

5. Kussie PH, Gorina S, Marechal V, Elenbaas B, Moreau J, et al. (1996) Structure of the MDM2 oncoprotein bound to the p53 tumor suppressor transactivation domain. Science 274: 948-953.

6. Grasberger BL, Lu T, Schubert C, Parks DJ, Carver TE, et al. (2005) Discovery and cocrystal structure of benzodiazepinedione HDM2 antagonists that activate p53 in cells. J Med Chem 48: 909-912.

7. Sakurai K, Schubert C, Kahne D (2006) Crystallographic analysis of an 8-mer p53 peptide analogue complexed with MDM2. J Am Chem Soc 128: 1100011001.

8. Popowicz GM, Czarna A, Wolf S, Wang K, Wang W, et al. (2010) Structures of low molecular weight inhibitors bound to MDMX and MDM2 reveal new approaches for p53-MDMX/MDM2 antagonist drug discovery. Cell Cycle 9 : 1104-1111.

9. Ding K, Lu Y, Nikolovska-Coleska Z, Wang G, Qiu S, et al. (2006) Structurebased design of spiro-oxindoles as potent, specific small-molecule inhibitors of the MDM2-p53 interaction. J Med Chem 49: 3432-3435.

10. Vine KL, Locke JM, Ranson M, Pyne SG, Bremner JB (2007) An investigation into the cytotoxicity and mode of action of some novel $\mathrm{N}$-alkyl-substituted isatins. J Med Chem 50: 5109-5117.

11. Ghandi M, Taheri A, Abbasi A (2010) A facile synthesis of chromeno [3, 4-c] spiropyrrolidine-oxindoles via 1, 3-dipolar cycloadditions. Tetrahedron 66: 6744-6748. 